\title{
ENVISIONING CREATIVE COLLABORATION BETWEEN FACULTY AND TECHNOLOGISTS
}

\author{
Gail A. Rathbun \\ Indiana University Purdue University Fort Wayne \\ Sally Kublenschmidt \\ Western Kentucky University \\ David Sacks \\ University of Kentucky
}

Faculty developers must often mediate conflicts resulting from differences between seemingly mutually exclusive cultures that university technologists and university teachers inhabit. Activity theory embraces workplace conflict as normal and as contributing to organizing bealth and adaptation, in contrast to a functionalist approach that focuses on how to maintain system equilibrium. Engeström's (1987) interpretation of activity theory provides a theoretically informed framework for understanding different forms of human activity, mediated by culturally molded rules, values, and division of labor, without suffering from the polarizing effects of an us-versus-them approach.

는

When it comes to collaborative work between faculty members and technologists, fiercely defended professional and disciplinary boundaries 
often prevent the constructive collaboration that is required to make effective use of technologies in teaching and learning. Three groups are involved in resolving these work relationships: faculty, technologists, and faculty developers. Faculty come with a variety of backgrounds but always are grounded within a specific discipline, as well as in the general tasks of working with students. Technologists, such as help desk personnel, hardware and software installers, evaluators of university systems, and instructional designers, arrive as specialists in the application of technological tools to support the academic mission. Faculty developers, in their role of organization developers and managers of curriculum development teams, find themselves helping these two groups to communicate. University technologists and university teachers inhabit seemingly mutually exclusive cultures, each with its own vocabulary, style of communication, values, organization of work, and orientations toward control and authority.

Acquiring knowledge about and understanding of diverse professional cultures is the first step to resolving conflict and building collaboration. The ways in which we come to understand cultures different from our own, however, often depend heavily on characterization and stereotype. Activity theory, as interpreted by Yrjo Engeström (1987), a Finnish social psychologist, provides a theoretically informed analytical framework for developing an understanding of different forms of human activity, without suffering from the polarizing effects of an us-versus-them approach. Activity theory embraces workplace conflict as normal and as contributing to organization health and adaptation.

The Professional and Organizational Development (POD) Network identifies three areas in which faculty developers are active: providing assistance to individual faculty in their teaching, research, and professional well-being; supporting curriculum development teams; and organizational development ("Faculty Development Definitions," n.d.). In each of these areas, the faculty developer is often situated as a facilitator, team leader, or project manager. Faculty developers thus often occupy interstitial spaces within the academic organization, frequently acting as buffers and interpreters, playing multiple roles as advocates, defenders, and neutral parties to interactions between and among technologists, faculty, administrators, and students. These roles demand of the faculty developer skills in leadership, organization, mediation, and communication. Joint analysis of the disturbances and conflicts inherent in collaborations among individuals who are situated in different communities of practice gives rise to resolutions of conflicts and the possibility of innovations in the structure and processes of the shared activity. 


\section{Conceptualizing Workplace Conflicts as Clashes between Cultures}

Technological change inevitably produces conflict or, at the very least, discomfort. To those involved, what pundits refer to as "disruptive innovation" is painful. Testifying to this fact are numerous articles examining the barriers to technology adoption in higher education, among them organizational and individual resistance to technology, exacerbated by tensions between academic and nonacademic subcultures. For example, Nicole Matthews's (2008) account of an attempt to promote web-supported learning among arts and sciences faculty at an Australian university is a typical tale of high hopes and minimal results produced by cultural clashes between administration, academic disciplines, and technologists. In particular, faculty viewed institutional goals for the integration of virtual learning environments into 100 percent of academic programs by a certain date with deep suspicion because of a general fear and dislike of centralized control. Technologists, or anyone else perceived as carrying out the institutional goal of cultural change, became the enemy. In another example, uneasiness around the necessary alliance of academics and technologists surfaced spontaneously in a session that Eleta Exline (2009), a university archivist, led at a regional conference dedicated to forging digital partnerships among librarians and technologists. The failure of members of these two groups to work together became the dominant theme of the session and prompted Exline to devote a decade to developing partnerships with technologists, including writing a literature review on the topic (2009). Several case studies in her review identify differences in professional culture as an obstacle to creative collaboration. Further testimony to the persistent presence of these cultural undercurrents is the 2011 POD listserv discussion of how faculty developers might deal with the cultural gulf between faculty and technologists (S. Kuhlenschmidt, personal communication, February 6, 2011).

Shahron Williams van Rooij (2011) elaborates on the nature of higher education subcultures and their roles in hindering adoption of open source software at universities in the United States. She identifies faculty, nontechnical teaching and research support staff, and other nontechnical staff working under the chief academic officer as members of the "academic subculture" Fundamental values underpinning this subculture are academic freedom and the concept of tenure, shared governance, the knowledge creation imperative, academic honesty (Williams van Rooij, 2011; American Association of University Professors, 2007), creativity, and autonomy ( $\mathrm{Lin} \& \mathrm{Ha}, 2009$ ). The technologist subculture consists of 
information technology staff; other technical staff such as help desk workers who support campus computing; instructional technologists; and instructional designers. Concepts fundamental to this subculture include efficiency, rationality (Robey \& Markus, cited in Leidner \& Kayworth, 2006), equality, competency, community, and progressivism (Scholz, cited in Leidner \& Kayworth, 2006). An earlier study by Williams van Rooij (2007) indicated that cultural conflict had been a significant hindrance to technology adoption at 772 institutions (Williams van Rooij, 2011). By 2011 a scarcity of resources had pushed the two cultures closer together, but the author concludes that maximizing the scarcer resources will depend on "striking a balance in which the drivers of one sub-culture are not realized at the expense of the other" (Williams van Rooij, 2011, p. 1182).

A mutually advantageous relationship between subcultures rests heavily on that cultural phenomenon called language and the ability to communicate clearly. In her essay, "The Techno-Humanist Interaction" (2010), Virginia Kuhn laments the communicative impasse between technologists and humanities scholars that impedes obvious synergies to be realized from collaboration. She describes a workshop bringing together supercomputing scientists and humanists in which the scientists "wondered how to manage data, whereas the [humanists] asked: 'Exactly what constitutes a datum?'” Kuhn continues, "While technologists imagine what could be, humanists imagine what should be" (p. 58). Miscommunication results in much wasted effort. Kuhn urges that we find a way to sustain "productive interaction . . . beginning in word and ending in action" (p. 58).

\section{Analyzing Cultural Conflict between Technologists and Academics}

Within the higher education institution reside occupational cultures such as technologists and academics. An occupational culture is the set of values, norms, and beliefs that guide its members in the workplace. In academia, the overarching cultures are those of teaching and research, and within those we find the subcultures of disciplines. Technologists have a few subcultures, and faculty developers may fall in either or both groups, as well as having a distinct culture of their own. What follows is a discussion and a critique of some of the models and theories that have been used to analyze and diagnose this and other cultural conflicts in higher education organizations.

To study organizational culture at a university in the Midwest, Tierney (1988) applied a framework of six elements based on an ethnographic approach inspired by the methods of anthropologists: environment, 
mission, socialization, information, strategy, and leadership. Tierney believed that by surfacing the elements of culture along with its assumptions, administrators might better detect and resolve conflict. A further assumption is that the reduction of conflict produces a benefit to the organization. Tierney's study falls squarely within the functionalist perspective (LeCompte \& Priessle, 1993), which holds as its major assumption that a system is composed of parts, each with a specific function that contributes to the overall health of the system. The goal of the functionalist analysis is to eliminate conflict and return the system to order. The case studies of conflict we will describe generally take a functionalist approach to examining the clash of information technology professional culture with faculty and academic cultures.

The study by Matthews (2008) is an example of a functionalist approach. The university that Matthews studied set as its goal to have 50 percent of all programs using virtual learning environments in two years and 100 percent of the university's programs within five years. Her critique is based on her identification of subcultures with widely varying values, goals, norms, and rules, and her recommendations are aimed at mitigating conflict between the fractious disciplinary "tribes" dwelling in the typical institution of higher education.

In another example of a functionalist approach. Davidson, Schofield, and Stocks (2001) studied the impact of professional cultures on collaboration between technologists and educators during a three-year project. They analyzed eighteen months of interviews, observations, and e-mails. From this analysis, they developed three meaningful cultural dimensions with which to interpret the behaviors and attitudes of the project members: routines, values, and orientations. Based on their findings, the researchers then offered insights into building successful collaborations and reducing conflict between technologists and educators.

Functionalist perspectives tend to focus on finding and describing different aspects of workplace culture, fragmenting the picture. The language and categories can be highly specialized. The functionalist approach does not integrate conflict, contradiction, and mutually influencing factors into its analysis. Finally, the approach tends to favor preservation of the status quo and perceives conflict as an aberration (LeCompte \& Priessle, 1993). Studies completed from this perspective fail to provide a basis for change and innovation in a variety of work contexts.

Activity theory, an analytical framework that falls within the theoretical perspective of conflict theory, offers a major advantage in teaching people how to use conflict to collectively reconstruct organization practices (Engeström, 1987). Conflict theory overlaps with the functionalist perspective but adds concepts such as dialectic, change, and contradiction. 
A conflict theory perspective argues that functionalism cannot fully explain change in social systems. Conflict theory embraces conflict and change as normal and as contributors to the overall health of a system. Given the disruptive innovations to higher education wrought by fast-moving technological change, the conflict theory perspective seems a better tool for addressing cultural conflict between faculty members and technologists. We did not find any exemplars in the literature of using this approach in facilitating the relationship between technologists and faculty members.

\section{A Brief Description of Activity Theory}

Cultural historical activity theory (CHAT) sits squarely within the conflict theory perspective. In CHAT, human activity is understood as an ongoing set of negotiations and evolving relationships, set in motion by disturbances or contradictions within or from outside the activity system. From these disturbances arises the potential to innovate and therefore alter the activity system. In this chapter, we refer to CHAT simply as "activity theory." The activity system is the basic unit of analysis in activity theory (Engeström, 1987). The activity system, represented by a triangular diagram, is based on Soviet psychologist Leont'ev's (1981) conception, later enhanced by Vygotsky (cited in Engeström, 1987), of mediated human actions. Subjects-individuals or groups-perform an action on an object with a specific motive to obtain an outcome using mediating tools such as machines, gestures, writing, drawings, or music. Leont'ev's conception of the activity system is shown in figure 2.1 as

Figure 2.1 Diagram of an Activity System

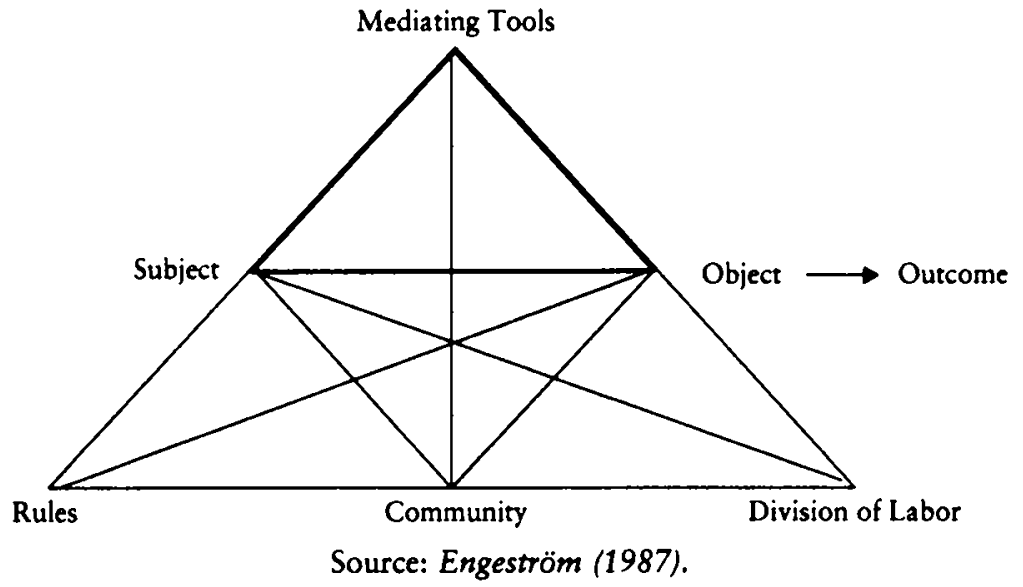


forming the tip of the triangle. Engeström widened the base of Leont'ev's simple triangle to include three primary elements of culture that influence the use of mediating tools:

o Rules, the explicit and implicit norms and conventions that enable and constrain action

o Community, which includes the individuals and groups that share the same object

o Division of labor, the horizontal division of tasks and vertical division of power and status

Activity theory emphasizes the key role of perspectives in understanding human activity, with these perspectives shaped by both the cultural and historical contexts of the activity. Understanding an activity requires analyzing the structure of the activity itself, how the cultural context shapes the activity, and the developmental history of that activity.

The elements of Engeström's conception (1987) of the activity system and examples of each element drawn from the context of higher education are shown in table 2.1.

\section{Applying Activity Theory in Workplace Contexts}

In this section we present examples of ways in which practitionerresearchers have used activity theory to uncover the causes of workplace disturbances and at the same time use the process and its results to evolve innovative practices and altered activity systems. Our goal is to illustrate the benefits and advantages of the activity theory framework for effecting positive change in the academic workplace, with an eye to how that could be applied to the relationships of technologists, faculty, and faculty developers.

In an example from the context of higher education, Benson, Lawler, and Whitworth (2008) observed that using activity theory caused them to shift their perspective of a course management system as an object to that of a mediational element: a tool, a set of rules, and a reflection of a division of labor. This was the way that the users perceived the systems that the researchers were examining; thus, activity theory helped the researchers to reframe the study in a manner more appropriate to their goal of understanding the different ways in which the two systems mediated the activities of users-in this case, college teachers and their online students.

The usefulness of activity theory in reframing the problem space was again evident in Scanlon and Issroff's (2005) experimentation with it as a new approach to evaluating learning technologies. They suggest that 
Table 2.1 The Seven Elements of the Activity System

\begin{tabular}{|c|c|c|}
\hline Element & Description of Element & Example of the Element \\
\hline Subject & $\begin{array}{l}\text { Individual or subgroup whose } \\
\text { actions are being analyzed }\end{array}$ & $\begin{array}{l}\text { Faculty member, technologist, } \\
\text { media developer }\end{array}$ \\
\hline Object & $\begin{array}{l}\text { Problem or material receiving } \\
\text { the action and which is } \\
\text { molded into an outcome }\end{array}$ & $\begin{array}{l}\text { The design of a course, a } \\
\text { software application, } \\
\text { instructional media }\end{array}$ \\
\hline Outcome & $\begin{array}{l}\text { Result of the subject's action } \\
\text { on an object }\end{array}$ & $\begin{array}{l}\text { Learning, a software selection, } \\
\text { engagement }\end{array}$ \\
\hline Rules & $\begin{array}{l}\text { Norms and conventions, both } \\
\text { implicit and explicit, that } \\
\text { constrain action }\end{array}$ & $\begin{array}{l}\text { Best practices, evaluation } \\
\text { checklist, instructional theory }\end{array}$ \\
\hline Tools & $\begin{array}{l}\text { Mediating instruments and signs } \\
\text { used by subject on object to } \\
\text { achieve outcome }\end{array}$ & Syllabus, flowcharts, \\
\hline Community & $\begin{array}{l}\text { Multiple individuals and } \\
\text { subgroups sharing the same } \\
\text { object and their shared values }\end{array}$ & $\begin{array}{l}\text { Faculty in a discipline, } \\
\text { instructional technologists, } \\
\text { instructional media } \\
\text { developers }\end{array}$ \\
\hline $\begin{array}{l}\text { Division of } \\
\text { labor }\end{array}$ & $\begin{array}{l}\text { Horizontal division of tasks and } \\
\text { vertical division of power and } \\
\text { status (complexity of the } \\
\text { work, control of the work, } \\
\text { task specialization) }\end{array}$ & $\begin{array}{l}\text { Faculty controls all tasks } \\
\text { (highly complex work); high } \\
\text { specialization of tasks, } \\
\text { coordinate work with others }\end{array}$ \\
\hline
\end{tabular}

activity theory allowed them to address problems in the evaluation of learning technologies having to do with poor definitions of criteria for success and the effects of context in choosing appropriate technology. The evaluators were able to expand the types of evaluation criteria and explain evidence of these criteria in terms of contradictions among rules, tools, division of labor, and outcomes. The notion of a contextualized activity system provided a language and framework for their evaluation of technologies and a way of incorporating inherent contradictions.

Paul Warmington's 2011 report on the Learning in and for Interagency Working (LIW) research project took place in the context of improving children's social services in the United Kingdom. The purpose of the application of activity theory in this project was to analyze current work practices and develop new ones that would reach across multiple professional roles. Warmington enumerates the LIW project's concerns, which are similar to ours: 
o The identification of new professional practices emerging within multiagency/multiprofessional settings

o The location of emergent multiagency/multiprofessional practice within an understanding of the changing character of service provision and user engagement

o The creation, through joint developmental work research (dwr) interventions, of new professional knowledge that might be levered into more effective multiagency/multiprofessional working

o The development and evaluation of activity theory/dwr derived methods as a tool both to analyze and to enhance professional learning. (p. 146)

Our last example has particular applicability for faculty development professionals. James Marken (2006) used Mwanza's (2001) eight-step model to guide the design and implementation of sales training for a Japanese sales force employed by a US Fortune 500 multinational company. In this case, cultural differences would be certain to emerge. Marken favored the use of Mwanza's model over Engeström's graphical representation for eliciting participation from teammates and clients. Marken's use (2006) of the eight-step model is summarized in table 2.2.

Mwanza (2001) then breaks down the activity triangle into what she calls the activity notation. Each activity notation includes an actor (subject or community), a mediator (tools, rules, or division of labor), and an object. Activity notations form small subactivities that are represented by lines drawn in the triangle between all of the elements of the activity system triangle.

When Marken plotted observations gained from using the eight-step model on the activity system triangle, he was able to explain relationships between contradictions and the mediating elements of the activity. The most important contradiction Marken's team had to resolve stemmed from a conflict between rules and division of labor. Social rules in Japan dictate that younger, less experienced people must not teach their elders, but all of the trainers were young and had not worked in Japan previously. The trainers received approval from senior Japanese leadership and made sure their trainees were aware of it. Marken claims that "by being able to name the contradiction we were able to bring the contradiction out and open it up for discussion" (p. 46). Other benefits from application of activity theory were a shared vocabulary and the ease with which members of the design team were able to use the idea of looking for contradictions to help them to solve problems. 


\section{Table 2.2 Marken's Use of Mwanza's Eight-Step Model}

\begin{tabular}{|c|c|c|}
\hline $\begin{array}{l}\text { Element of } \\
\text { Activity }\end{array}$ & Identifying Question & Marken's Response \\
\hline $\begin{array}{l}\text { Activity of } \\
\text { interest }\end{array}$ & $\begin{array}{l}\text { What sort of activity am I } \\
\text { interested in? }\end{array}$ & $\begin{array}{l}\text { Training program/preparing } \\
\text { for the program }\end{array}$ \\
\hline $\begin{array}{l}\text { Object or } \\
\text { objective of } \\
\text { activity }\end{array}$ & $\begin{array}{l}\text { Why is this activity taking } \\
\text { place? What will change as } \\
\text { a result of this activity? }\end{array}$ & $\begin{array}{l}\text { Coaching skills and support } \\
\text { for business objectives }\end{array}$ \\
\hline $\begin{array}{l}\text { Subjects in this } \\
\text { activity }\end{array}$ & $\begin{array}{l}\text { Who is involved in carrying } \\
\text { out this activity? }\end{array}$ & $\begin{array}{l}\text { Japanese and US trainers, } \\
\text { sales team leaders, sales } \\
\text { managers, business unit } \\
\text { managers }\end{array}$ \\
\hline $\begin{array}{l}\text { Tools mediating } \\
\text { the activity }\end{array}$ & $\begin{array}{l}\text { By what means are the } \\
\text { subjects carrying out this } \\
\text { activity? }\end{array}$ & $\begin{array}{l}\text { Selling process workshop, } \\
\text { district focus week review, } \\
\text { role plays, case studies, } \\
\text { equipment, room }\end{array}$ \\
\hline $\begin{array}{l}\text { Rules and } \\
\text { regulations } \\
\text { mediating the } \\
\text { activity }\end{array}$ & $\begin{array}{l}\text { Are there any cultural norms, } \\
\text { rules, or regulations } \\
\text { governing the performance } \\
\text { of this activity? }\end{array}$ & $\begin{array}{l}\text { Hierarchy in age and rank, } \\
\text { don't speak first, share } \\
\text { your experience, training } \\
\text { must be relevant and } \\
\text { realistic }\end{array}$ \\
\hline $\begin{array}{l}\text { Division of } \\
\text { labor } \\
\text { mediating the } \\
\text { activity }\end{array}$ & $\begin{array}{l}\text { Who is responsible for what, } \\
\text { when carrying out this } \\
\text { activity, and how are the } \\
\text { roles organized? }\end{array}$ & $\begin{array}{l}\text { Presenters and their tasks, } \\
\text { debriefers and their tasks, } \\
\text { technical support and their } \\
\text { tasks }\end{array}$ \\
\hline $\begin{array}{l}\text { Community in } \\
\text { which } \\
\text { activity is } \\
\text { conducted }\end{array}$ & $\begin{array}{l}\text { What is the environment in } \\
\text { which this activity is } \\
\text { carried out? }\end{array}$ & $\begin{array}{l}\text { Company, country of Japan, } \\
\text { company units, peer } \\
\text { companies }\end{array}$ \\
\hline Outcome & $\begin{array}{l}\text { What is the desired outcome } \\
\text { from carrying out this } \\
\text { activity? }\end{array}$ & $\begin{array}{l}\text { Enhanced district sales } \\
\text { manager performance, } \\
\text { increased sales, increase in } \\
\text { sales rank as compared } \\
\text { with other companies }\end{array}$ \\
\hline
\end{tabular}

\section{Activity Theory and Creative Collaboration}

If college students are to receive the fullest benefit from their academic experience, faculty must be able to use the latest technologies well enough to craft meaningful learning experiences and pursue the scholarly work that informs and is informed by their teaching. Faculty development professionals play vital roles in providing interpretation of the role of technology in pedagogy and as scholars of teaching and learning. Activity 
theory is a useful addition to the developer's tool kit for improving communication and pedagogical effectiveness.

Some common activity systems in the faculty developer's work environment are teaching, consulting, learning, evaluation, relationship building, course design, and evaluation of teaching, to name a few. To determine whether activity theory as an analytical framework could lead to a less polarized perspective of faculty and IT professional cultures and help achieve the goal of creative collaboration, we developed several scenarios (we include one in this chapter) based on our own professional experiences as technologists, faculty members, faculty developers, and instructional designers, with additional input from faculty development colleagues participating in a 2011 POD listserv conversation (Sacks, Rathbun, \& Kuhlenschmidt, 2011).

Our own analysis of the discussion revealed several broad areas in which faculty's and technologists' perspectives differed sharply. Each scenario featured a conflict between a faculty member and a technologist arising from one of the following orientations: toward time, toward process, and toward security of the information system. We then analyzed these conversations, identifying activity system elements and disturbances, using Engeström's (1987) graphical representation of an activity system. Because interactions between technologists and faculty frequently occur in the context of seeking and obtaining advice or recommendations concerning the use of computer hardware, software, and networks, we constructed an activity system of consulting viewed from two perspectives: that of the technologist and that of the faculty member. We applied the basic concepts of activity theory to this scenario:

Faculty: (on phone to IT help) I'm reviewing the drafts of some of my graduate research papers, and I'm having a very difficult time with the plagiarism detection software. l'm hoping you can help me.

Technologist: I'll sure try. Hang on a second, and I'll set up a remote session that will connect to your computer from my computer, if that's okay with you. That way we'll both have control over your desktop. Faculty: (slowly, a little doubtful) Oh ... okay, if you think that will help. Technologist: (a few minutes pass) Just about there. Thanks for your patience. (another moment passes)

Technologist: Okay, you should be able to see my mouse on your screen. Now what's the problem?

Faculty: The software isn't checking the papers against professional journals, even though we have subscriptions in the library database. Is this feature turned off for some reason? 
Technologist: Let me check into that. I'll go up here into the database list and see. Well, as you can see, the list of databases includes only things posted on the web and in paper mills on the Internet. There's not much I can do about not having professional journals in the list. These are what come with the program we bought. Can I do anything else to help you with this software?

Faculty: (starting to become visibly irritated) No. That isn't going to solve my problem. Who can help me with adding to the number of searchable databases?

Technologist: Uh, think the software specifications were drawn up by Tom in the academic software support unit. They do a thorough review of available options. Reviewing tech is their specialty.

Faculty: Did faculty have any input on the choice so that these issues about source being plagiarized were discussed? How was the final decision made?

Technologist: I don't know, but I am sure that Tom could answer your questions. Hold on, and I'll transfer you. I don't think he's gone for the day. If he is, you can leave a message.

Using Mwanza's activity notation, which includes an actor (subject or community), a mediator (tools, rules, or division of labor), and an object, we identified two subactivities within the activity system as the primary sources of disturbance. The first sign of disturbance (the gray triangle marked " 1 " in figure 2.2) is the faculty member's doubtful reaction to the eagerness of the help desk technician to fulfill his request for help with the plagiarism detection software. Following the rules of the help desk, the technician reacts speedily and asks permission to take control of the desktop, an established protocol for handling a question originating from the user's work station. Respectful of the technician's knowledge, the faculty member does not protest. The faculty member asks what seems like another technical question, at the same time indicating that he has already done some research into the problem, which seems to confirm that this is a technical question the help desk can answer. The rules of the help desk, reinforced by the values of the technologist community, do not satisfactorily mediate obtaining the faculty member's outcome. The technologist, however, may be able to record this interaction as "question answered," that is, outcome achieved.

Another rule of the help desk, asking if there is anything else the technician can do, actually serves to annoy the faculty member, providing a segue into the second disturbance (the gray triangle marked " 2 " in figure 2.2). Here the disturbance stems from the specialization of tasks 


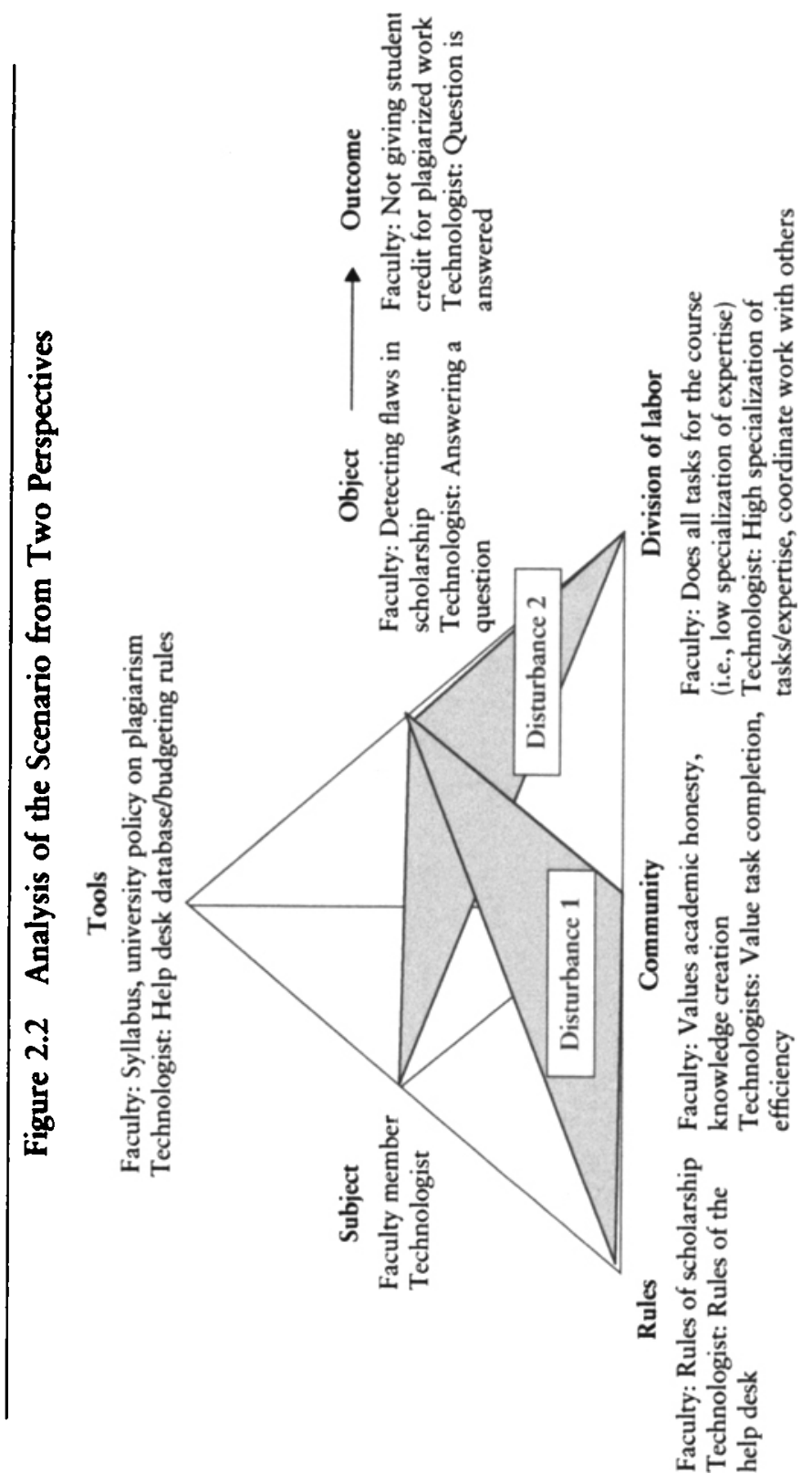


and expertise-the division of labor. The faculty member expects a greater breadth of knowledge from the technician, much like the breadth of knowledge expected of the faculty member. At the same time, the faculty member presumes that the academic software support unit does not have the appropriate knowledge to select plagiarism software. Responsibility for selecting this type of software, according to the faculty member, should be assigned to faculty. In this subactivity, neither the faculty member nor the technologist achieves his or her respective objectives or outcomes. The help desk rule that when the technician cannot answer a question he or she should find someone who can results in an unsatisfactory end to the interaction.

Our sample analysis of a typical technologist-faculty conversation isolated two nodes of conflict that technologists and faculty members could focus on together using a shared vocabulary. Using the methods described in this chapter, our scenario of a conflict of cultures may be reframed as a shared design problem-the design of processes and the organization of work-to achieve the outcomes of the activity system of technology consulting. In this situation, it is not necessary for all parties to have knowledge of activity theory, though it would be helpful. The faculty developer acting as a mediator or a team leader can meet with the help desk manager and the faculty member. The faculty developer could call attention to the difference in the technician's and the faculty member's intended outcomes and in the values guiding their respective behaviors. New shared values could emerge, such as the importance of precision and clarity in communication and suggestions for reprioritizing the value clarity over speed in help desk operations. A dialogue about the negative effects of task specialization could begin, and proposals for redrawing lines of communication between organization units could develop. The faculty developer is uniquely positioned to initiate and implement these changes in the organization of work and in work culture across boundaries of discipline, organizational functions, and professional cultures.

Faculty developers can take advantage of their roles as professional developers and scholarly practitioners to teach the basic activity theory concepts to their technologist and faculty colleagues, much as Marken (2006) did. He taught activity theory to the global sales and marketing team of a US multinational company as part of the development of a sales training retreat for the Japanese affiliate. Marken used Mwanza's (2001) eight-step model to introduce the fundamental concepts. Team members found this approach easier to use than the Engeström (1987) model, though they did employ the framework somewhat. As part of the process of development, team members interviewed Japanese managers and 
analyzed these interviews and their own considerable knowledge of Japanese culture using activity theory. Potential cultural conflicts were uncovered that changed the design of the training and shaped the expectations of the trainers (Marken, 2006). In a similar fashion, the faculty developer might bring together representatives of the technologist and faculty cultures to learn activity theory together and jointly analyze their shared workplace. From such joint systematic study, the potential for organization change is created.

\section{Conclusion}

Painstaking analyses of occupational subcultures from a functionalist theoretical perspective have shed much light on the structure of institutions of higher education, their goals for instructional technologies, and the nature and impact of occupational subcultures. Understanding the role of professional culture, however, does not necessarily lead to constructive adaptation to technological change or to the development of innovative work processes. The theoretical perspective of activity theory, building on functional analysis of the workplace, integrates conflict, disturbances, and contradictions into a coherent description of shared work activity. At the same time, activity theory provides a way for coworkers residing in diverse communities of practice to collaboratively envision new ways to transform the academic workplace in support of achieving institutional goals.

The case studies, including our own scenario presented here, illustrate the negative effects of conflicts between the technologists and faculty members on the design and implementation of technologies in higher education. Divergent ways of defining and solving a particular problem can lead to confusion, mistrust, disappointment, and failure to resolve anything. Faculty give up trying to use technologies that could be helpful or quit consulting with technologists for help, and technologists lose respect for faculty work or fail to consult with them when it is needed for the better functioning of the university. How much better education would be if these two divergent viewpoints, this diversity, could be meshed to create stronger, more effective pedagogy and more efficient uses of technology.

\section{REFERENCES}

American Association of University Professors. (2007). Informal glossary of AAUP terms and abbreviations. Retrieved from http://www.aaup.org /AAUP/about/mission/glossary.htm 
Benson, A., Lawler, C., \& Whitworth, A. (2008). Rules, roles and tools: Activity theory and the comparative study of e-learning. British Journal of Educational Technology, 39(3), 456-467.

Davidson, A. L., Schofield, J., \& Stocks, J. (2001). Professional cultures and collaborative efforts: A case study of technologists and educators working for change. Information Society, 17, 21-32.

Engeström, Y. (1987). Leaming by expanding: An activity-theoretical approach to developmental research. Helsinki, Fl: Orienta-Konsultit.

Exline, E. (2009). Working together: A literature review of campus information technology partnerships. Jourmal of Archival Organizations, 7, 16-23.

Faculty Development Definitions. (n.d.). Retrieved from http:/www.podnetwork .org/faculty_development/definitions.htm

Kuhn, V. (2010). The techno-humanist interaction. Educause Review, 45(6), 58-59.

LeCompte, M. D., \& Priessle, J. (1993). Ethnography and qualitative design in educational research. San Diego, CA: Academic Press.

Leidner, D. E., \& Kayworth, T. (2006). A review of culture in information systems research: Toward a theory of technology culture conflict. MIS Quarterly, 30(2), 357-399.

Leont'ev, A. N. (1981). The problem of activity in Soviet psychology. In J. V. Wertsch (Ed.), The concept of activity in Soviet psychology (pp. 37-71). Armonk, NY: Sharpe.

Lin, C., \& Ha, L. (2009). Subcultures and use of communication information technology in higher education institutions. Joumal of Higher Education, $80(5), 564-590$.

Marken, J. A. (2006). An application of activity theory: A case of global training. Performance Improvement Quarterly, 19, 27-49.

Matthews, N. (2008). Conflicting perceptions and complex change: Promoting web-supported learning in an arts and social sciences faculty. Learning, Media and Technology, 33(1), 35-44.

Mwanza, D. (2001). Where theory meets practice: $A$ case for an activity theory based methodology to guide computer system design. Retrieved from http:/I kmi.open.ac.uk/publications/techreports.html

Sacks, D., Rathbun, G., \& Kuhlenschmidt, S. (2011). Bridging faculty and IT cultures. Retrieved from https:/sites.google.com/a/podnetwork.org /wikipodia/Home/topics-for-discussion/bridging-faculty-and-it-cultures

Scanlon, E., \& Issroff, K. (2005). Activity theory and higher education: Evaluating learning technologies. Journal of Computer Assisted Learning, 21, $430-439$.

Tierney, W. G. (1988). Organizational culture in higher education: Defining the essentials. Journal of Higher Education, 59(1), 2-21. 
Warmington, P. (2011). Divisions of labour: Activity theory, multi-professional working and intervention research. Journal of Vocational Education and Training, 63(2), 143-157.

Williams van Rooij, S. (2007). Open source software in higher education: Reality or illusion? Education and Information Technologies, 12(4), 191-209.

Williams van Rooij, S. (2011). Higher education sub-cultures and open source adoption. Computers and Education, 57, 1171-1183. 